\title{
The Influence of COVID-19 Stay at Home Measures on Fire Statistics Sampled from New York City, London, San Francisco, and Tokyo
}

\author{
Sayaka Suzuki @*, National Research Institute for Fire and Disaster \\ (NRIFD), Chofu, Tokyo, Japan \\ Samuel L. Manzello (1), National Institute of Standards and Technology \\ (NIST), Gaithersburg, MD, USA
}

Received: 27 April 2021/Accepted: 2 September 2021/Published online: 21 September 2021

\begin{abstract}
The COVID-19 pandemic kept people at home, in either a voluntary or non-voluntary capacity, in many countries. These suggested countermeasures were prominent in the so-called initial waves of the pandemic, especially from March 2020 to May 2020. As people stayed home, in many cases restaurants were closed. As a result, people spent more time in their kitchen, not only to cook meals but also as a personal hobby. It is well known that cooking fires are a main cause of fires in residential homes. In this study, the change in the number of cooking fires in residential homes as well as the number of residential fires during these COVID-19 countermeasure periods were examined in four cities: New York City (USA), San Francisco (USA), Tokyo (Japan), and London (UK). The time period examined was from January to June in 2020 in order to grasp overall effects of stay-at-home measures on fire incidents. The number of cooking fires and residential fires increased in Tokyo and San Francisco, while the number of cooking fires in New York City (no data was obtained for cooking fires in London.) and the number of residential fires in New York City and London remained similar to previous years.
\end{abstract}

Keywords: Fire statistics, Cooking fires, Residential fires, COVID-19, Stay-at-home measures

\section{Introduction}

The global pandemic from COVID-19 resulted in not only loss of lives but a major adjustment to millions of people's situations in many countries. The COVID-19 pandemic forced people to stay at home. In some countries, this was voluntary while in other countries, this was in a non-voluntary capacity. People stayed home, and it was impossible to dine-in as restaurants were ordered to close their dine-in service. As a result, people spent more time in their kitchens, not only to cook meals but also as a personal hobby $[1,2]$.

\footnotetext{
*Correspondence should be addressed to: Sayaka Suzuki, E-mail: sayakas@fri.go.jp
} 
It is well known that cooking fires are a main cause of fires in residential homes, along with cigarette induced fires [3-5]. The number of residential fires increases in the afternoon to night, when people stay home, and are awake, peaking around dinner time. Cigarette induced fires, and resulting deaths, increase at night when people are sleeping [3-5].

In the case of the COVID-19 pandemic, many people stayed home and worked from home. While it is not possible to determine cooking habits of all of residents on a global basis, it is reasonable to assume people cooked more due to the restaurant closures. Thus, it is expected people staying home and cooking more often may have effects on fire incidents during the COVID-19 pandemic. In this study, the change in the number of cooking fires in residential homes, as well as the number of residential fires, during so-called initial waves of the COVID-19 pandemic were investigated. Four cities were examined: New York City (USA), San Francisco (USA), Tokyo (Japan), and London (UK).

\section{Methods}

\subsection{Selection of Cities}

An important part of understanding fire losses in many countries consider the collection and reporting of annual fire statistics. In the UK, statistics were collected and reported from the loss of urban structures during World War II. In 1976, the USA created the National Fire Incident Reporting System, known simply as NFIRS. Similarly, in Japan, urban fire statistic collection began after World War II.

Four cities, New York City (USA), San Francisco (USA), Tokyo (Japan), and London (UK), were selected in this study. These cities were investigated based on the following considerations: (1) these cities are large enough to have relatively large number of cooking fires per month, (2) it was easy to access raw data, and (3) they had different COVID-19 situations and countermeasures.

During the period of examination, New York City was considered one of the hardest hit by the COVID-19 pandemic, as evidenced by the large number of reported cases as shown in Fig. 1. San Francisco reported far fewer cases of COVID-19 during this period. New York City and San Francisco implemented lockdown measures [6-9]. Tokyo did not have so many reported COVID-19 cases but was on alert far earlier than the other cities examined here due to the Diamond Princess cruise ship situation. Tokyo was never locked down by government order but declared a state of emergency, with voluntary stay-at-home orders [10]. The UK was hoping to achieve herd immunity initially without lockdown but quickly changed course and resorted to lockdown measures [11, 12]. Table 1 is summary of each city's approach and lockdown duration. 


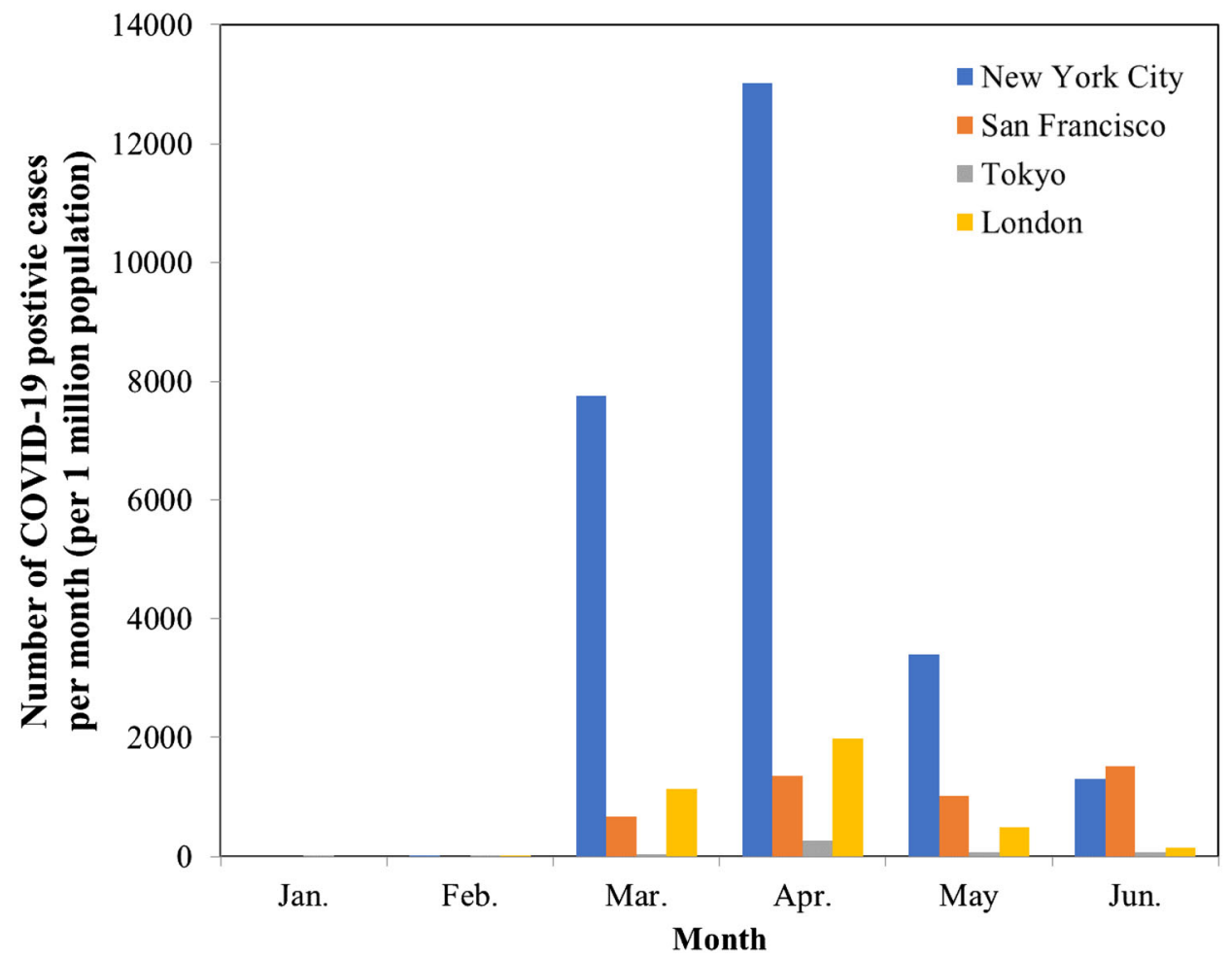

Figure 1. Number of COVID-19 positive cases per month (per 1 million population) calculated based on open data source [ 1 3-1 6 ].

\subsection{Data Collection}

The fire incident data was obtained from open database sites [17-21]. All of these data across four cities were "reported" data, and not corrected for analysis, as the purpose of this study is to grasp the overall effects across the different cities.

\section{Analysis}

Comparing fire statistics among different countries needs attention as definitions may differ. As a baseline, the fire statistics of each city from the past 5 years was compared first. Some of analysis on the fire trend has already been published elsewhere [20-22]. Attention was paid as terminology or categories may be different among countries. This is an issue discussed also elsewhere when comparing the fire statistics among countries [23]. It is important to mention that the data were "reported fires", thus unreported fires-most of smaller fires, are not included [24].

The number of residential fires, and the number of cooking fires in the first 6 months of 2020 were compared with those in the first 6 months of 2015 to 2019 


\section{Table 1}

Approach and Lockdown/Stay-at-Home Duration of Each City

\begin{tabular}{|c|c|c|c|c|}
\hline & New York City & San Francisco & Tokyo & London \\
\hline $\begin{array}{l}\text { Contents } \\
\text { of lock- } \\
\text { down/ } \\
\text { stay-at- } \\
\text { home } \\
\text { measures }\end{array}$ & $\begin{array}{l}\text { Stay-at-home (All } \\
\text { non-essential busi- } \\
\text { ness closed. Resi- } \\
\text { dents are allowed } \\
\text { only "essential" } \\
\text { purpose. Order is } \\
\text { mandantory, while } \\
\text { it was indicated no } \\
\text { individual would be } \\
\text { fined.) }\end{array}$ & $\begin{array}{l}\text { Shelter in place or } \\
\text { stay-home (all non- } \\
\text { essential business } \\
\text { closed. Residents } \\
\text { are allowed to go } \\
\text { outside for only } \\
\text { "essential" purpose. } \\
\text { Order is mandan- } \\
\text { tory.) }\end{array}$ & $\begin{array}{l}\text { Declaration of State } \\
\text { of Emergency. (all } \\
\text { non-essential busi- } \\
\text { ness closed. Resi- } \\
\text { dents are allowed to } \\
\text { go outside for only } \\
\text { "essential" purpose. } \\
\text { Order is not man- } \\
\text { dantory.) }\end{array}$ & $\begin{array}{l}\text { Lockdown. (All } \\
\text { non-essential busi- } \\
\text { ness closed. Resi- } \\
\text { dents are allowed } \\
\text { only "essential" } \\
\text { purpose. Order is } \\
\text { mandantory. Limi- } \\
\text { tation on outside } \\
\text { activities.) }\end{array}$ \\
\hline $\begin{array}{l}\text { Lockdown } \\
\text { duration } \\
\text { or emer- } \\
\text { gency } \\
\text { declara- } \\
\text { tion }\end{array}$ & $\begin{array}{l}\text { March 22nd to June } \\
\text { 7th }\end{array}$ & $\begin{array}{l}\text { March 19th to May } \\
\text { 7th }\end{array}$ & $\begin{array}{l}\text { April 8th to May } \\
\text { 26th }\end{array}$ & $\begin{array}{l}\text { March 26th to July } \\
\text { 4th }\end{array}$ \\
\hline
\end{tabular}

(average value). In this study, a comparison of past 5 years data was selected for comparison. The use of 5-year average data has been presented elsewhere [20, 21]. In addition, the purpose of this study is to see the 'big picture' of how stay-athome measures influenced fires in four cities.

The average data of 2015 to 2019 was used for comparison. The data in London needs an attention, as there were decreases in the total number of fires, and residential fires in last 5 years [22]. For London, the data [19] does not contain information on cooking fires, and no comparison with that in London was performed. Table 2 provides "categories" used to count the number of each fire.

\section{Results}

\subsection{Trend on the Number of Residential Fires}

The residential fires in all four cities are shown in Fig. 2. The number of residential fires in both New York City (Fig. 2a) and San Francisco (Fig. 2b) during the first six months of 2020 are within the uncertainties of average (2 standards deviations) with a small increase observed in San Francisco's May. For Tokyo, the number of residential fires in 2020 remains similar to the average except May, which shows an increase (Fig. 2c). The number of residential fires in 2020 (Fig. 2d) in London is lower than the average of last 5 years, due to the decrease in the number of residential fires in general in London. Overall, the number of residential fires in those four cities was observed to be similar to average, expect that in May in Tokyo. 


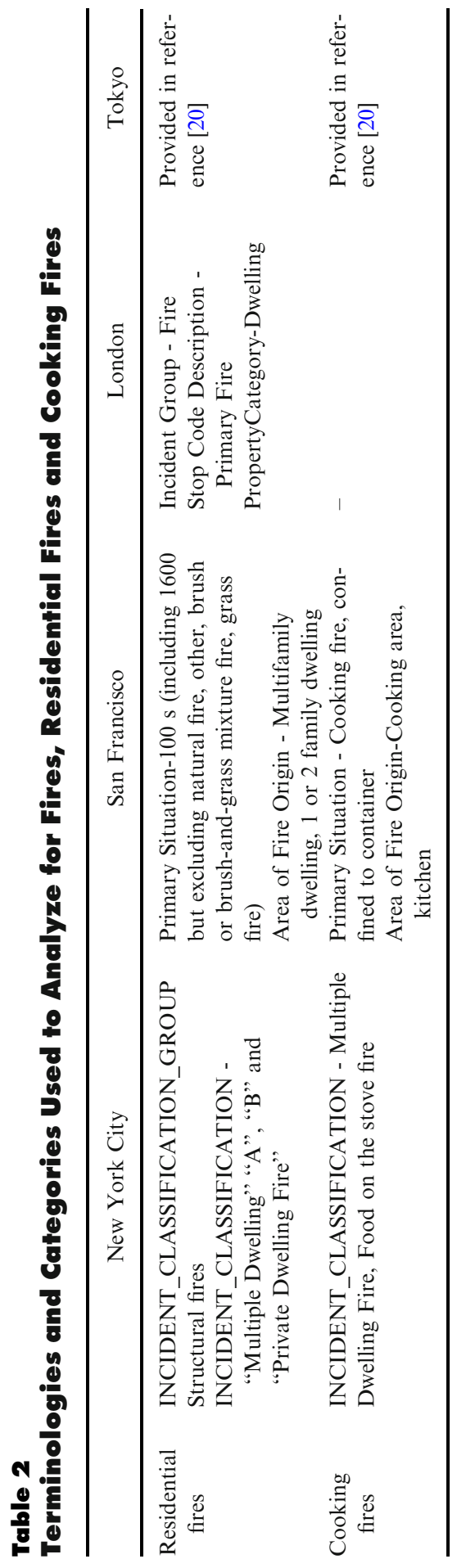


(a)

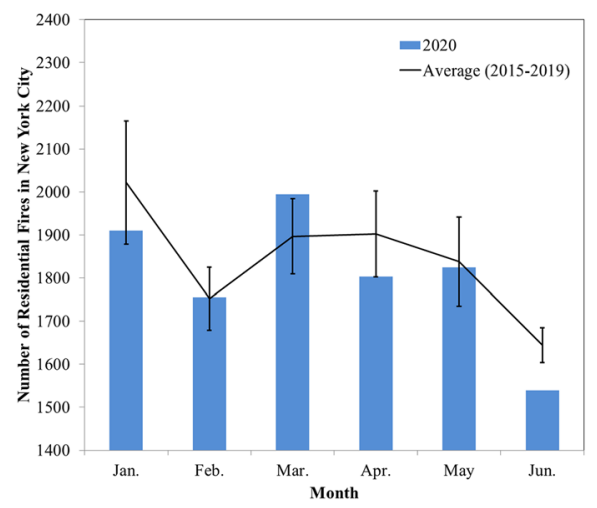

(c)

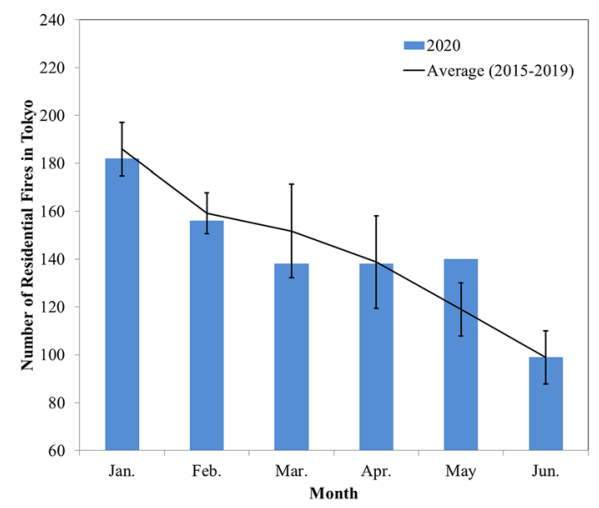

(b)

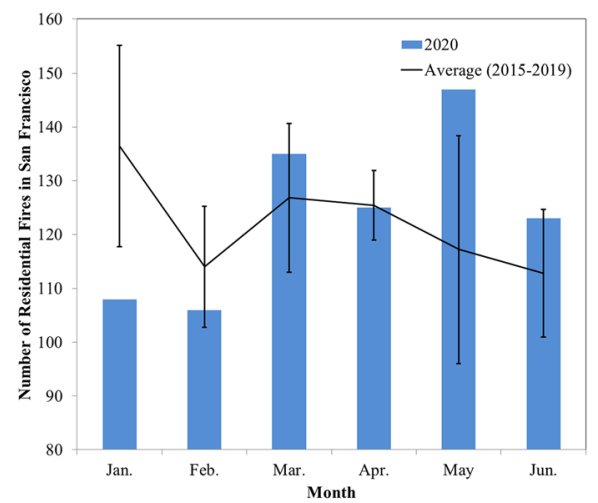

(d)

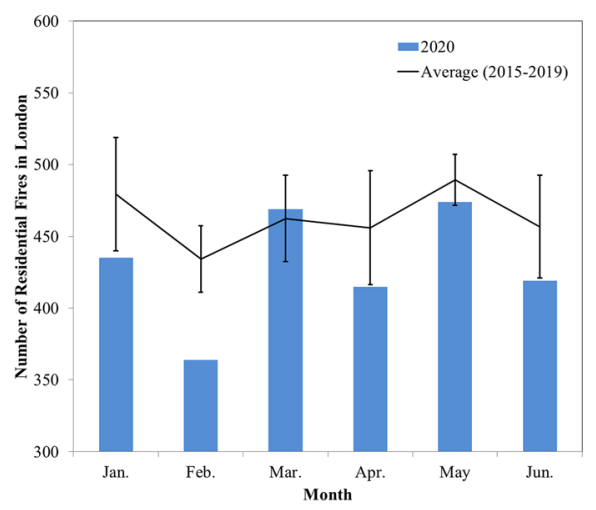

Figure 2. Number of residential fires in the period of January to June a New York b San Francisco c Toky॰ d London.

\subsection{Trend on the Number of Cooking Fires}

The number of cooking fires in New York City, shown in Fig. 3a, started increasing in February, peaked in March, and started decreasing in April. In the case of San Francisco (see Fig. 3b), the number of cooking fires is clearly higher from March to May. In January, February, and June, the number is slightly higher than the average. In the case of Tokyo (see Fig. 3c), the increase in May is more than $50 \%$ up from the average. Smaller peak in February is observed. The increase in April and May in Tokyo and San Francisco are similar while a different trend is observed in New York. 
(a)

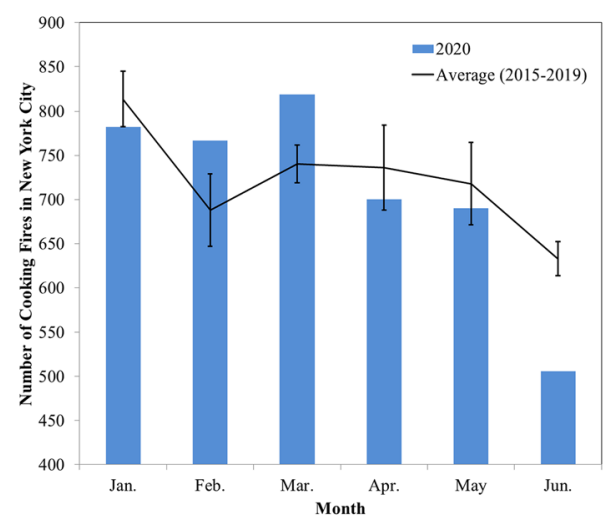

(b)

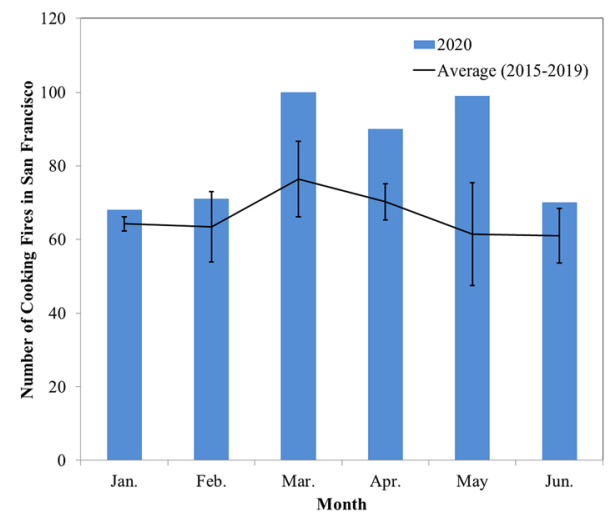

(c)

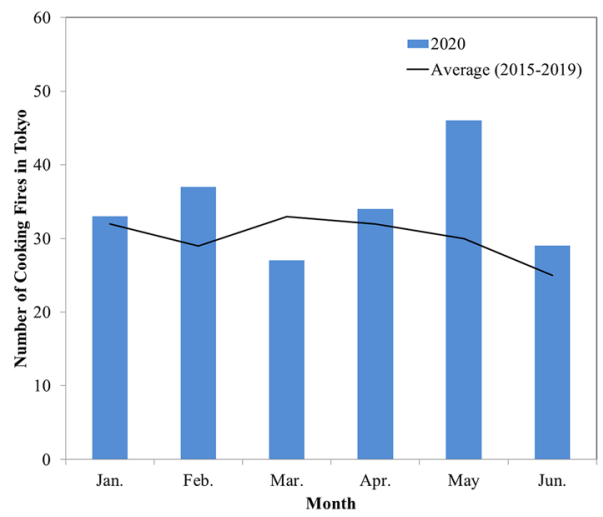

Figure 3. Number of cooking fires in the period of January to June a New York b San Francisco c Tokyo.

\section{Discussion}

The situation in each city was different-London and New York City had a high number of COVID-19 cases while Tokyo and San Francisco had less during the stay-at-home period shown in Fig. 1. As shown in Table 1, the general approach to lockdown or stay-at-home in New York City, San Francisco and London was similar (mandatory) while people in Tokyo stayed home on more "voluntary" basis. Community mobility reports, such as google or apple, indicate more people stayed home, or less commuted to work in all four cities [25, 26]. This being said, the trend on the number of residential fires and cooking fires in each city, are not clear. For residential fires, the numbers increased in San Francisco and Tokyo, while it did not in London and New York City. For cooking fires, the numbers increased in San Francisco and Tokyo, while it did not in New York City. These 
findings are interesting since residents were forced to stay home and spent time in cooking.

The simple comparison did not provide general increases or decreases in the numbers of residential fires or cooking fires. Possible reasons for these findings may be in cultural differences, including cooking habits in those cities, and response to the COVID-19 pandemic. The option for carry-out should be also investigated Additionally, cooking habits may change when carry-out became available in general.

London and New York City were considered one of the worst hit cities during those stay-at-home period, and high demands for first responders for COVID-19 patients might have prevented people from calling the fire department or people were afraid to let first responders into their home if a fire was small. This needs further investigation, including more data from different countries as well as cultural aspects, including comparison of socioeconomic factors [27, 28]. Furthermore, investigating the number of fire incidents before and after the lockdown periods provide new insights on fire statistics. For example, short-term comparisons on residential fires or cooking fires is also possible from a stay-at-home viewpoint as well as people's approach to fires or reporting fires.

\section{Conclusion}

The number of fires, especially residential fires and cooking fires, are compared with the previous 5 years for the first 6 month of 2020 (January to June) in New York City, San Francisco, London, and Tokyo in order to investigate the effect of stay-at-home order on the number of fires. No clear trend was observed among the four cities. The number of residential fires increased during the stay-at-home period in San Francisco and Tokyo, while the percentage of residential fires in all fires in New York City increased during the stay-at-home period and both remains similar for London. The number of cooking fires increased in San Francisco and Tokyo, while it did not increase in New York City. One possible explanation for this is the number of COVID-19 cases. The dispatch call number is the same for ambulance and fire, and people hesitated to call fire department if a fire was small due to high demand of first responders or to let first responders into their home. This needs more investigation including more data from different counties and taking into cultural aspects.

\section{References}

1. The rise of home cooking in lockdown Trends and Insights 2020-2021 https://thebilling tongroup.com/news/2021/01/19/the-rise-of-home-cooking-in-lockdown-trends-and-insigh ts-2020-2021/

2. From Cooking to calligraphy, people stuck at home are finding new space for creativity https://www.washingtonpost.com/nation/2020/04/11/cooking-calligraphy-people-stuck-h ome-are-finding-new-space-creativity/ 
3. Spearpoint M, Hopkin C (2020) A study of the time of day and room of fire origin for dwelling fires. Fire Technol 56:1465-1485. https://doi.org/10.1007/s10694-019-00934-5

4. Japan Syoboucho, "Shobo Hakusyo (Heisei 30 Nenban)" (2006) Gyosei

5. Ahrens M, Maheshwari R (2020) Home structure fires, NFPA Research, November 2020

6. Timeline: The first 100 days of New York Gov. Andrew Cuomo's COVID-19 response, abc news https://abcnews.go.com/US/News/timeline-100-days-york-gov-andrew-cuomoscovid/story?id =71292880 (Accessed April 2021)

7. Here's what a 'stay home' order means for New York, The Guardian, https://www.theg uardian.com/us-news/2020/mar/20/new-york-90-day-stay-home-order-what-it-means (Accessed April 2021)

8. City and County of San Francisco, Order of the Health Officer of the City and County of San Francisco Directing All Individuals Living in the County to Shelter at their Place of Residence Except that they may Leave to provide or Receive Certain Essential Services or Engage in Certain Essential Activities and Work for Essential Business and Government Services; Exempting Individuals Experiencing Homelessness from the Shelter in Place Order but Urging Them to find Shelter and Government Agencies to Provide it; Directing all Businesses and Governmental Agencies to Cease Non-Essential Operations at Physical Locations in the County; Prohibiting all Non-Essential Gatherings of any Number of Individuals; and Ordering Cessation of all Non-Essential Travel (Shelter in Place) Date of Order: March 16, 2020, Order of the Health Officer No. C1907 Department of Public Health Order of the Health Officer, City and County of San Francisco

9. News: SF responds to coronavirus outbreak with Stay Home order, https://sf.gov/news/ sf-responds-coronavirus-outbreak-stay-home-order (Accessed April 2021)

10. Novel Coronavirus Response Headquarters, 27th meeting, April 7th 2020, Prime Minister's Office of Japan https://www.kantei.go.jp/jp/98_abe/actions/202004/07corona.html (Accessed April 2021)

11. The Health Protection (Coronavirus, Restrictions) (England) Regulations 2020

12. Herd immunity: will the UK's coronavirus strategy work?, The Guardian, https://www. theguardian.com/world/2020/mar/13/herd-immunity-will-the-uks-coronavirus-strategy-w ork (Accessed April 2021)

13. COVID-19 Daily Counts of Cases, Hospitalizations, and Deaths, NYC OpenData, http s://data.cityofnewyork.us/Health/COVID-19-Daily-Counts-of-Cases-Hospitalizations-an /rc75-m7u3

14. COVID-19 Cases and Deaths, Data SF https://data.sfgov.org/stories/s/dak2-gvuj

15. Details of COVID-19 patients, Tokyo government Open Data Catalog site, https://catal og.data.metro.tokyo.lg.jp/dataset/t000010d0000000068/resource/c2d997db-1450-43fa-803 7 -ebb11ec28d4c

16. Coronavirus (COVID-19) Cases, London Datastore https://data.london.gov.uk/dataset/ coronavirus-covid-19-cases

17. Fire Incident Dispatch Data, NYC OpenData https://data.cityofnewyork.us/Public-Safe ty/Fire-Incident-Dispatch-Data/8m42-w767 (Accessed April 2021)

18. Fire Incidents, DataSF https://data.sfgov.org/Public-Safety/Fire-Incidents/wr8u-xric (Accessed April 2021)

19. London Fire Brigade Incident Records, London Database https://data.london.gov.uk/d ataset/london-fire-brigade-incident-records (Accessed April 2021)

20. Tokyo Fire Department, Koho 2020 nenn 10 gatsu https://www.tfd.metro.tokyo.lg.jp/c amp/2020/202010/camp1.html (Accessed April 2021) 
21. Kasai no Jittai, Tokyo Fire Department e-library, https://www.tfd.metro.tokyo.lg.jp/hpcyousaka/kasaijittai/index.html (Accessed April 2021)

22. Home Office, Fire and rescue incident statistics: England year ending September $2020 \mathrm{~h}$ ttps://assets.publishing.service.gov.uk/government/uploads/system/uploads/attachment_d ata/file/959838/fire-and-rescue-incident-sep20-hosb0521.pdf

23. Fire Safety -Statistical data collection- part 2: definition of terms, ISO/DIS 17755-2(en)

24. Greene MA, Andres C (2004-2005) National sample survey of unreported residential fires, July 2009, CPSC https://www.cpsc.gov/s3fs-public/UnreportedResidentialFires.pdf (Accessed April 2021)

25. Google, Community Mobility Report https://www.google.com/covid19/mobility/ (Accessed April 2021)

26. COVID-19-Mobiliy Trends Reports-Apple, https://covid19.apple.com/mobility (Accessed April 2021)

27. Jenning C (1999) Scoioeconomic characteristics and their relationship to fire incidence: a review of the literature. Fire Technol 35(1):7-34

28. Beaulieu E, Smith J, Zheng A, Pike I (2019) Association between neighbourhood socioeconomic features and residential fire incidence, related casualties and children: a cross-sectional population-based study in 4 Canadian provinces. CMAJ Open 7(3):E562-E567. https://doi.org/10.9778/cmajo.20190079

Publisher's Note Springer Nature remains neutral with regard to jurisdictional claims in published maps and institutional affiliations. 